\title{
Efficiency Comparison of Municipal Public Transport in the Selected Cities of the Czech Republic
}

\author{
Veronika KOMOROUSOVÁ and Jana HINKE* \\ University of West Bohemia, Pilsen, Czech Republic; vkomoro@kfu.zcu.cz; hinke@kfu.zcu.cz \\ * Corresponding author: hinke@kfu.zcu.cz
}

\begin{abstract}
The article compares the efficiency of municipal public transport in the cities of Pilsen and Ostrava. To compare the efficiency, a system of suitable ratios has been drawn up. The ratios were calculated from the underlying data in the time series from 2010 to 2019. First, the transport services in both cities were compared on the basis of the following indicators: density of the transport network, transport facilities, comparative transport capacity, the development of the average age of public transport vehicles in comparison with the development of investments in the vehicle fleet recalculated per unit of performance. Subsequently, the comparison of efficiency was drawn, with the parameter of capacity utilization of transport performance being chosen as the basic criterion. The analysis was complemented with a comparison of real sales per capita, a comparison of nominal sales per passenger transported and a comparison of the real value of compensation per capita. Based on the comparisons, the conclusions were drawn. They show that although the city of Ostrava has relatively better public transport facilities, the city of Pilsen uses its public transport more efficiently.
\end{abstract}

Keywords: efficiency; municipal public transport; comparison; transport performance

JEL Classification: L91; O18

\section{Introduction}

Increasingly frequent traffic congestions and the growing interest in environmental issues make public transport the preferred mode of transport in cities. Therefore, national and local authorities should determine operating conditions that will enable the efficient use of public funds (Fitzova \& Matulova, 2020). However, the question is how to evaluate the efficiency of municipal public transport, and thus the effectiveness of the use of public funds.

To assess the efficiency of priorities of public transport, the authors (Zhang et al., 2019) designed an index system using the difference coefficient of the CRITIC-TOPSIS model. The obstacle factor model is used to diagnose factors influencing the priority performance of municipal public transport. Lupták et al. (2019) propose a new uniform methodology for the assessment of passenger transport timetables in terms of transport connectivity, the purpose of which is to propose a methodological procedure for assessing the quality of transport connections in the transport network, thus heading towards a more efficient evaluation of integrated transport systems. The study (Hirschhorn et al., 2019) on the organization and performance of public transport focused on the selected metropolitan areas in Europe, Australia and Canada uses the qualitative comparative analysis (QCA). The QCA uses a 
combination of multiple explanatory conditions, examines the relations between the conditions and evaluates their necessity and adequacy. The return on costs depends on the combined effects of several conditions and finds out that different ways can lead to similar results. Other authors (Anila et al., 2019) used the AHP technique (Analytical Hierarchical Process) to evaluate performance indicators. The methodology of model construction begins with the selection of various performance indicators. Twelve variables were selected for the model. They were then divided into user-oriented and provider-oriented indicators. A worldwide survey by the Dephi technique was used in another study (Hirschhorn et al., 2018) to evaluate the performance indicators and organizational elements in public transport. This is a three-phase iterative process of interweaving questionnaires and controlled feedback. In relation to the performance indicators, system-wide metrics are selected as the preferred measures for the strategic evaluation of public transport. Alonso et al. (2018) assesses the efficiency of public transport in times of financial/economic crisis. Their results show that especially the growth of transport integration can improve the efficiency and quality of public transport, and thus contribute to increasing the competitiveness of public transport (even in adverse contexts). In any case, Campos-Alba et al. (2020) highlight the need to analyze the long-term effectiveness of various forms of public transport management, as this is the only way to obtain a stable, homogeneous, and comparable estimate of the efficiency of municipal public transport.

Matulova and Fitzova (2018) conducted research in this area within the Czech Republic. They examined the efficiency of municipal public transport using three external inputs (employees, rolling stock, and energy), one final output (passengers), and two intermediate products (vehicle-kilometers and seat-kilometers). One of their main findings was that the efficiency of smaller transport systems which had a difficult access to funding sources was systematically less efficient. In other research, Fitzova et al. (2018) identified factors influencing the efficiency of municipal public transport systems and compared Czech municipal public transport systems according to their efficiency. This analysis was performed on a sample of 19 systems in the Czech Republic for the period from 2010 to 2015. According to their results, Pilsen had one of the most efficient transport systems, in contrast to the least efficient cities: Chomutov-Jirkov, Ostrava and Dein. This paper will verify the results of their study and further determine whether the position of the selected cities of Pilsen and Ostrava has changed since the time of the research to the present.

The purpose of the paper is to examine the often-ignored area of public transport, which can significantly affect the growing density of traffic in cities and the efficiency of transport networks. The municipal public transport system has its own specifics, it is an area with imperfect competition, which is often regulated by the state. Hence, the measurability of the effectiveness and efficiency of this activity has its limitations, and it is difficult to use general criteria and metrics to evaluate performance.

In this paper, the authors aim to determine which of the selected cities has better public transport facilities and which city uses public transport more efficiently. 


\section{Methodology}

The efficiency comparison of municipal public transport was made between two cities of the Czech Republic, namely Pilsen and Ostrava. The main criterion for selection was primarily comparability in the mode of transport services by public transport, with three transport modes being represented in both cities, i.e., trams, trolleybuses, and buses. The selected cities are also comparable in terms of area and population.

The data collection for the analysis was made from the period of 2010-2019 (Table 1). We used data from the annual reports of the Association of Public Transport Companies, data published by the Czech Statistical Office and data from the Ministry of Transport. After that we defined a system of suitable indicators for comparison, both for the evaluation of transport services and then for the evaluation of transport efficiency. We calculated the indicators in the monitored time series and added average values as well. We compared the values of the indicators, subsequently drew partial conclusions, and summarized them overall.

\section{Results}

First, the transport services in both cities were compared within the efficiency comparison of municipal public transport. The following criteria were chosen to evaluate the transport services: density of the transport network, transport facilities, comparative transport capacity, the development of the average age of public transport vehicles in comparison with the development of investments in the vehicle fleet. Subsequently, the efficiency comparison was performed, with the parameter of capacity utilization of transport performance being chosen as the basic criterion. The analysis was complemented by the comparison of sales per capita and per passenger transported as well as by the comparison of the real value of compensation per capita.

\subsection{Comparison of Transport Services Provided by Municipal Public Transport}

We have defined the following parameters for the basic comparison of transport services:

- Density of the public transport network (the network in $\mathrm{km} /$ the area in $\mathrm{km}^{2}$ ) was determined as the quotient of the length of public transport lines in $\mathrm{km}$ and the area of the city in $\mathrm{km}^{2}$.

- The parameter of transport facilities per thousand of inhabitants (the transport network in $\mathrm{km} /$ the number of inhabitants) was determined as the quotient of the length of public transport lines and the number of inhabitants $(x 1,000)$.

- Comparative transport capacity (in thousands of seat-kilometers per capita) was determined as the quotient of performance in thousands of seat-kilometers and the number of inhabitants.

- The parameter of capital expenditures per unit of performance (in millions of $\mathrm{CZK} /$ performance in vehicle-kilometers) was determined as the quotient of capital expenditures in millions of CZK and transport performance in vehicle-kilometers. 
- The parameter of the development of the average age of vehicles in total was quantified as the average age of vehicles by individual modes of transport (tractions). The average value was calculated as a simple average, in 2019 the average value was specified by a weighted average, where the weights were the number of vehicles of individual modes of transport (tractions) (the data in the result table are given in brackets).

Based on the development of individual parameters and their comparison (Table 2), the following conclusions have been drawn:

- The city of Ostrava has better public transport services in terms of the density of the transport network, with an average of $5 \mathrm{~km}$ of lines per one $\mathrm{km}^{2}$ of the city area. In Pilsen, there is an average of $4 \mathrm{~km}$ of lines per $\mathrm{km}^{2}$ of the city area.

- When comparing the ratio of the length of the public transport network to the number of inhabitants, Ostrava has also slightly better public transport network, with $3.54 \mathrm{~km}$ of lines per 1,000 inhabitants compared to $3.23 \mathrm{~km}$ of lines per 1,000 inhabitants in Pilsen.

- The comparison of recalculated transport capacity is also better for Ostrava, which has the annual average of 11.5 thousand of seat-kilometers per capita. In Pilsen, there is on average 8.6 thousand of seat-kilometers per capita per year.

- As for the equipment of the vehicle fleet concerning its innovation, then Pilsen invests more in the purchase and modernization of public transport, with investing an average of CZK 15.61 per vehicle-kilometer of transport performance per year. In Ostrava, it is on average CZK 12.17 per vehicle-kilometer of transport performance. The comparison result of capital expenditures also corresponds to the development of the average age of vehicles, when Pilsen uses a newer vehicle fleet for transport services (the average age of vehicles is approx. 9 years), while Ostrava has slightly older vehicles for public transport services (approx. 13 years).

\subsection{Comparison of Efficiency of Municipal Public Transport}

To compare the efficiency of municipal public transport, we have defined the following parameters:

- The number of rides per capita was determined as the ratio of transport performance in the number of passengers transported to the number of inhabitants. This is a parameter indicating the number of rides (passengers transported) per inhabitant of the city per year.

- The indicator of transport performance in passenger-kilometers (determined by multiplying the performance of passengers transported and the average transport distance) is commonly used to evaluate transport performance, with this parameter indicating the transport of one passenger over the distance of one kilometer. The transport performance of municipal public transport in passenger-kilometers is published by the Ministry of Transport for the entire Czech Republic, not for individual transport companies. The indicator of transport performance in passenger-kilometers for the selected transport companies was recalculated from the data on passengers 
transported and from the data on the average transport distance according to the statistics of the Ministry of Transport (Table 3).

- The efficiency of transport performance - the so-called utilization of transport capacity (in \%) - was determined as the ratio of transport performance in passenger-kilometers to transport performance in seat-kilometers. This indicator gives us the percentage utilization of transport capacity.

- The value of real sales from public transport per capita was determined as the ratio of the real value of sales to the number of inhabitants. To recalculate the nominal value of sales to real value, the accumulated inflation indices (Table 4) related to the base year of 2010 were used. The inflation indices were determined based on the development of the annual inflation rate according to the Czech Statistical Office (2021a).

- The value of nominal sales from public transport per passenger transported was determined as the ratio of the nominal value of sales to the value of transported passengers. This indicator is a certain approximate identifier of the fare price.

- The real value of compensation per capita (in CZK) was determined as the ratio of the real value of compensation for public transport to the number of inhabitants. To recalculate the nominal value of compensation to real value, basic inflation indices were used again. This indicator shows the degree of social costs of operating municipal public transport (the value of subsidies per capita).

Based on the development of individual parameters and their comparison (Table 5), the following conclusions were drawn:

- When comparing the indicator of the number of rides per capita, it was found that the city of Ostrava falls behind Pilsen by almost half, with an average of 322 passengers transported per one inhabitant in Ostrava, in contrast to Pilsen, where there are 625 passengers transported per one inhabitant.

- The indicator of the transport performance efficiency points to the fact that the capacity of public transport in Ostrava is used at $21 \%$ on average, while in Pilsen the average use of public transport capacity is at $55 \%$.

- The indicator of real value of sales per capita also points to the fact that public transport is used more efficiently in Pilsen, where there is an average of CZK 1,592 of real sales per capita, while it is a slightly lower value in Ostrava on average (CZK 1,536 of sales per capita); although there is a $33 \%$ higher capacity of transport performance per capita (in passenger-kilometers) in Ostrava.

- The indicator of the nominal value of sales per passenger transported is a certain complementary indicator for evaluating the efficiency. It determines the average price of rides excluded VAT in general. This indicator provides some generalizing information about the pricing strategy of the compared cities. It may be deduced from the indicator that travelling by municipal public transport is generally cheaper in Pilsen than in Ostrava. When comparing the passenger fare rates, in addition to comparing the price of basic passenger fare rates, it would also be necessary to compare the system of discounts 
and options when passenger fares are free, and to take into account the structure of passengers, which is not the subject of this article.

- A certain degree of social costs per capita can be deduced from the indicator of the real value of compensation per capita. The results clearly show that in Pilsen there is a share of CZK 4,361 per capita on average per year, which is by $22 \%$ higher subsidies from public budgets to municipal public transport per capita than in Ostrava, where the average amount is CZK 3,563.

\section{Discussion and Conclusions}

The research concerning the assessment of the efficiency of municipal public transport focused on the comparison of transport services and subsequently on the comparison of the efficiency of municipal public transport in the cities of Pilsen and Ostrava. Based on the analysis of the defined system of indicators from the time series of 2010-2019, the following conclusions have been drawn:

- In this comparison, the city of Ostrava has a higher transport capacity and better public transport facilities than Pilsen (a higher density of the public transport network, a higher calculated length of the network per capita and a higher transport capacity per capita).

- On the other hand, the city of Pilsen has a higher quality of public transport in terms of fleet innovation indicators (a lower average age of vehicles, higher average investments in fleet modernization and renewal).

- The city of Pilsen uses its municipal public transport more efficiently (a higher value of transport performance in terms of transported passengers per capita, a higher use of transport performance capacity based on the efficiency parameter). In Pilsen, there is also a higher volume of real sales per capita, although it is possible to deduce that Pilsen provides public transport with a generally more favorable pricing strategy (a lower value of nominal sales per passenger transported). The analysis also points to the fact that the social costs expressed in the ratio of subsidies for municipal public transport per capita are higher in Pilsen than in Ostrava.

Based on the summary of partial conclusions, it can be stated that although the city of Ostrava has a higher density of the public transport network and better facilities than Pilsen, it uses its public transport with significantly lower efficiency. In Pilsen, on the other hand, there is a better equipped vehicle fleet in terms of its age and modernization, and a more favorable pricing strategy for passengers can be found as well. However, the population in Pilsen is burdened by higher social costs on average (subsidies from public budgets), which go to public transport.

In further research, we would like to focus on comparing the efficiency of municipal public transport in other cities of the Czech Republic, to gradually complement the research with analysis of other related indicators, to add a deeper analysis of pricing strategy, to examine the impact of public transport efficiency on transport sustainability (especially emissions, noise, and traffic density), and to evaluate the interdependence - correlation of individual variables in longer time series. 
Table 1. The underlying data for the calculation of comparative indicators. (Own processing in accordance with Association of Transport Companies of the Czech Republic, 2021).

\begin{tabular}{|c|c|c|c|c|c|c|c|c|c|c|}
\hline \multirow{2}{*}{ Municipal public transport - Ostrava } & \multicolumn{10}{|c|}{ Year } \\
\hline & 2010 & 2011 & 2012 & 2013 & 2014 & 2015 & 2016 & 2017 & 2018 & 2019 \\
\hline Transport performance in thousands of $\mathrm{km}$ & 34,054 & 34,008 & 33,773 & 32,214 & 31,820 & 32,168 & 32,546 & 32,751 & 32,703 & 31,814 \\
\hline Transport performance in thousands of seat-km & $3,462,884$ & $3,475,436$ & $3,469,792$ & $3,311,458$ & $3,301,825$ & $3,298,709$ & $3,331,316$ & $3,353,975$ & $3,348,643$ & $3,336,729$ \\
\hline Passengers transported (in thousands of passengers) & 102,600 & 101,924 & 96,389 & 93,476 & 91,000 & 88,159 & 88,518 & 91,150 & 97,648 & 96,129 \\
\hline The length of lines (in km) & 1,068 & 1,068 & 1,059 & 1,000 & 1,025 & 1,027 & 1,014 & 1,014 & 1,057 & 1,069 \\
\hline Sales from municipal public transport in mil. of CZK & 514 & 516 & 520 & 531 & 511 & 481 & 452 & 435 & 429 & 441 \\
\hline Compensation (public transport subsidies) in mil. of CZK & 1,022 & 1,025 & 1,083 & 1,070 & 1,062 & 1,033 & 1,064 & 1,177 & 1,306 & 1,409 \\
\hline Compensation (percentage of costs) & 66 & 66 & 67 & 66 & 67 & 67 & 69 & 75 & 77 & 78 \\
\hline Investments in vehicle fleet in mil. of CZK & 303.6 & 280.2 & 316.0 & 170.7 & 277.3 & 847.7 & 0.0 & 41.5 & $1,178.8$ & 556.9 \\
\hline Average age - buses & & 9.4 & 8.8 & 8.8 & 10.0 & 5.8 & 6.6 & 7.6 & 6.7 & 6.9 \\
\hline Average age - trolleybuses & & 12.0 & 11.9 & 12.6 & 13.6 & 11.5 & 11.6 & 11.9 & 9.7 & 10.6 \\
\hline Average age - trams & & 15.7 & 15.7 & 20.0 & 19.5 & 21.5 & 22.0 & 23.0 & 20.1 & 19.6 \\
\hline Number of inhabitants & 303,609 & 299,622 & 297,421 & 295,653 & 294,200 & 292,681 & 291,634 & 290,450 & 289,128 & 287,968 \\
\hline Area of the city in $\mathrm{km}^{2}$ & 214.2 & 214.2 & 214.2 & 214.2 & 214.2 & 214.2 & 214.2 & 214.2 & 214.2 & 214.2 \\
\hline
\end{tabular}

\begin{tabular}{|c|c|c|c|c|c|c|c|c|c|c|}
\hline \multirow{2}{*}{ Municipal public transport - Pilsen } & \multicolumn{10}{|c|}{ Year } \\
\hline & 2010 & 2011 & 2012 & 2013 & 2014 & 2015 & 2016 & 2017 & 2018 & 2019 \\
\hline Transport performance in thousands of $\mathrm{km}$ & 15,036 & 15,078 & 15,102 & 15,071 & 15,077 & 15,099 & 15,238 & 15,283 & 15,065 & 15,460 \\
\hline Transport performance in thousands of seat-km & $1,381,428$ & $1,360,527$ & $1,371,334$ & $1,415,689$ & $1,437,851$ & 1,486124 & $1,494,694$ & 1,585469 & $1,479,127$ & $1,535,859$ \\
\hline Passengers transported (in thousands of passengers) & 100,885 & 101,900 & 99,154 & 100,593 & 101,115 & 101,986 & 107,581 & 109,984 & 115,473 & 124,977 \\
\hline The length of lines (in $\mathrm{km}$ ) & 487 & 487 & 472 & 541 & 581 & 582 & 583 & 587 & 586 & 593 \\
\hline Sales from municipal public transport in mil. of CZK & 273 & 267 & 300 & 296 & 292 & 290 & 292 & 292 & 293 & 303 \\
\hline Compensation (public transport subsidies) in mil. of CZK & 690 & 742 & 743 & 766 & 798 & 816 & 777 & 824 & 872 & 930 \\
\hline Compensation (percentage of costs) & 65 & 63 & 63 & 60 & 61 & 63 & 63 & 62 & 63 & 38 \\
\hline Investments in vehicle fleet in mil. of CZK & 232.8 & 273.2 & 309.0 & 209.2 & 175.0 & 188.6 & 83.5 & 247.0 & 44.5 & 610.7 \\
\hline Average age - buses & & 10.1 & 9.0 & 7.1 & 8.1 & 7.3 & 6.9 & 8.2 & 9.1 & 7.5 \\
\hline Average age - trolleybuses & & 10.9 & 12.0 & 5.4 & 8.5 & 8.6 & 8.5 & 6.7 & 7.4 & 7.8 \\
\hline Average age - trams & & 8.3 & 8.3 & 6.6 & 9.1 & 9.0 & 9.0 & 10.8 & 11.8 & 11.8 \\
\hline Number of inhabitants & 168,808 & 167,302 & 167,472 & 168,034 & 169,033 & 169,858 & 170,548 & 170,936 & 172,441 & 174,842 \\
\hline Area of the city in $\mathrm{km}^{2}$ & 137.7 & 137.7 & 137.7 & 137.7 & 137.7 & 137.7 & 137.7 & 137.7 & 137.7 & 137.7 \\
\hline
\end{tabular}


Table 2. Parameters for the comparison of transport services by public transport for the period of 2010-2019. (own processing)

\begin{tabular}{|c|c|c|c|c|c|c|c|c|c|c|c|}
\hline & 2010 & 2011 & 2012 & 2013 & 2014 & 2015 & 2016 & 2017 & 2018 & 2019 & Average \\
\hline \multicolumn{12}{|c|}{ Network density ( $\mathrm{km}$ of lines/area in $\left.\mathbf{k m}^{2}\right)$} \\
\hline Ostrava & 4.99 & 4.99 & 4.94 & 4.67 & 4.79 & 4.79 & 4.73 & 4.73 & 4.93 & 4.99 & 4.86 \\
\hline Pilsen & 3.53 & 3.53 & 3.43 & 3.93 & 4.22 & 4.23 & 4.23 & 4.26 & 4.26 & 4.31 & 3.99 \\
\hline \multicolumn{12}{|c|}{$\begin{array}{l}\text { Transport facilities } \\
\text { (in km of lines per thousand of inhabitants) }\end{array}$} \\
\hline Ostrava & 3.52 & 3.56 & 3.56 & 3.38 & 3.48 & 3.51 & 3.48 & 3.49 & 3.66 & 3.71 & 3.54 \\
\hline Pilsen & 2.88 & 2.91 & 2.82 & 3.22 & 3.44 & 3.43 & 3.42 & 3.43 & 3.40 & 3.39 & 3.23 \\
\hline \multicolumn{12}{|c|}{$\begin{array}{l}\text { Transport capacity (in thousands of seat-km } \\
\text { per the number of inhabitants) }\end{array}$} \\
\hline Ostrava & $11,405.74$ & $11,599.40$ & $11,666.26$ & $11,200.49$ & $11,223.06$ & $11,270.66$ & $11,422.93$ & $11,547.51$ & $11,581.87$ & $11,587.15$ & $11,450.51$ \\
\hline Pilsen & $8,183.43$ & $8,132.16$ & $8,188.44$ & $8,425.02$ & $8,506.33$ & $8,749.21$ & $8,764.07$ & $9,275.22$ & $8,577.58$ & $8,784.27$ & $8,558.57$ \\
\hline \multicolumn{12}{|c|}{$\begin{array}{l}\text { Capital expenditures per unit of performance } \\
\text { (in CZK/km) }\end{array}$} \\
\hline Ostrava & 8.92 & 8.24 & 9.36 & 5.30 & 8.71 & 26.35 & 0.00 & 1.27 & 36.05 & 17.50 & 12.17 \\
\hline Pilsen & 15.48 & 18.12 & 20.46 & 13.88 & 11.61 & 12.49 & 5.48 & 16.16 & 2.95 & 39.50 & 15.61 \\
\hline \multicolumn{12}{|c|}{ Average age of vehicles (in years) } \\
\hline Ostrava & & 12.37 & 12.13 & 13.80 & 14.37 & 12.93 & 13.40 & 14.17 & 12.17 & $12.37(12.7)$ & 13.08 \\
\hline Pilsen & & 9.77 & 9.77 & 6.37 & 8.57 & 8.30 & 8.13 & 8.57 & 9.43 & $9.03(9.0)$ & 8.66 \\
\hline
\end{tabular}

Table 3. Average transport distance from 2010 to 2019. (Sydos, 2021)

\begin{tabular}{|c|c|c|c|c|c|c|c|c|c|c|}
\hline & 2010 & 2011 & 2012 & 2013 & 2014 & 2015 & 2016 & 2017 & 2018 & 2019 \\
\hline Average transport distance & 6.9 & 7.1 & 7.1 & 7.5 & 7.6 & 7.4 & 7.6 & 7.7 & 8.2 & 8.3 \\
\hline
\end{tabular}

Table 4. Basic inflation index from 2010 to 2019. (Czech Statistical Office, 2021b)

\begin{tabular}{|c|c|c|c|c|c|c|c|c|c|c|}
\hline & 2010 & 2011 & 2012 & 2013 & 2014 & 2015 & 2016 & 2017 & 2018 & 2019 \\
\hline Basic inflation index & 100 & 101.8 & 104.9 & 106.3 & 106.7 & 107 & 107.7 & 110.1 & 112.3 & 115.1 \\
\hline
\end{tabular}


Table 5. Parameters for comparing the efficiency of municipal public transport for the period of 2010-2019. (own processing)

\begin{tabular}{|c|c|c|c|c|c|c|c|c|c|c|c|}
\hline & 2010 & 2011 & 2012 & 2013 & 2014 & 2015 & 2016 & 2017 & 2018 & 2019 & Average \\
\hline \multicolumn{12}{|c|}{ Number of rides per capita } \\
\hline Ostrava & 338 & 340 & 324 & 316 & 309 & 301 & 304 & 314 & 338 & 334 & 322 \\
\hline Pilsen & 598 & 609 & 592 & 599 & 598 & 600 & 631 & 643 & 670 & 715 & 625 \\
\hline \multicolumn{12}{|c|}{$\begin{array}{l}\text { Transport performance (in thousands of } \\
\text { passenger-kilometers) }\end{array}$} \\
\hline Ostrava & 707,940 & 723,660 & 684,362 & 701,070 & 691,600 & 652,377 & 672,737 & 701,855 & 800,714 & 797,871 & 713,419 \\
\hline Pilsen & 696,107 & 723,490 & 703,993 & 754,448 & 768,474 & 754,696 & 817,616 & 846,877 & 946,879 & $1,037,309$ & 804,989 \\
\hline \multicolumn{12}{|c|}{ Transport performance efficiency (in \%) } \\
\hline Ostrava & $20 \%$ & $21 \%$ & $20 \%$ & $21 \%$ & $21 \%$ & $20 \%$ & $20 \%$ & $21 \%$ & $24 \%$ & $24 \%$ & $21 \%$ \\
\hline Pilsen & $50 \%$ & $53 \%$ & $51 \%$ & $53 \%$ & $53 \%$ & $51 \%$ & $55 \%$ & $53 \%$ & $64 \%$ & $68 \%$ & $55 \%$ \\
\hline \multicolumn{12}{|c|}{ Real value of sales per capita (in CZK) } \\
\hline Ostrava & 1,693 & 1,692 & 1,666 & 1,690 & 1,629 & 1,537 & 1,439 & 1,360 & 1,320 & 1,331 & 1,536 \\
\hline Pilsen & 1,616 & 1,567 & 1,708 & 1,656 & 1,620 & 1,596 & 1,588 & 1,552 & 1,513 & 1,507 & 1,592 \\
\hline \multicolumn{12}{|c|}{$\begin{array}{l}\text { Nominal value of sales per passenger } \\
\text { transported (in CZK) }\end{array}$} \\
\hline Ostrava & 5.0 & 5.1 & 5.4 & 5.7 & 5.6 & 5.5 & 5.1 & 4.8 & 4.4 & 4.6 & 5.1 \\
\hline Pilsen & 2.7 & 2.6 & 3.0 & 2.9 & 2.9 & 2.8 & 2.7 & 2.7 & 2.5 & 2.4 & 2.7 \\
\hline \multicolumn{12}{|c|}{$\begin{array}{l}\text { Real value of compensation calculated } \\
\text { per capita (in CZK) }\end{array}$} \\
\hline Ostrava & 3,366 & 3,360 & 3,471 & 3,405 & 3,383 & 3,299 & 3,388 & 3,681 & 4,022 & 4,251 & 3,563 \\
\hline Pilsen & 4,087 & 4,357 & 4,229 & 4,288 & 4,425 & 4,490 & 4,230 & 4,378 & 4,503 & 4,621 & 4,361 \\
\hline
\end{tabular}


Acknowledgements: This paper is a partial result of the SGS-2020-026 project titled "Economic and Financial Transformation in the Context of the Digital Society" of the Faculty of Economics, University of West Bohemia in Pilsen.

\section{References}

Alonso, A., Monzón, A., \& Cascajo, R. (2018). Measuring negative synergies of urban sprawl and economic crisis over public transport efficiency: the case of Spain. International Regional Science Review, 41(5), 540-576. https://doi.org/10.1177/0160017616687361

Anila, C., Raviraj, M., \& Varghese, G. (2019). Performance Optimization of Public Transport Using Integrated AHP-GP Methodology. Urban Rail Transit, 5(2), 133-144. https://doi.org/10.1007/s40864-019-0103-2

Association of Transport Companies of the Czech Republic. (2021). About us - Annual reports. Retrieved January 2, 2021 from http://www.sdp-cr.cz/o-nas/vyrocni-zpravy/

Campos-Alba, C. M., Prior, D., Pérez-López, G., \& Zafra-Gómez, J. L. (2020). Long-term cost efficiency of alternative management forms for urban public transport from the public sector perspective. Transport Policy, 88, 16-23. https://doi.org/10.1016/j.tranpol.2020.01.014

Czech Statistical Office. (2021a). Public database - own choice. Retrieved January 10, 2021, from https://vdb.czso.cz/vdbvo2/faces/cs/index.jsf?page=uziv-dotaz\#.

Czech Statistical Office. (2021b). Inflation - types, definitions, tables. (n.d.). Inflation - Types, Definitions, Tables. Retrieved January 8, 2021, from https://www.czso.cz/csu/czso /mira_inflace

Fitzova, H., \& Matulova, M. (2020). Comparison of urban public transport systems in the Czech Republic and Slovakia: Factors underpinning efficiency. Research in Transportation Economics, 81(SI). https://doi.org/10.1016/j.retrec.2020.100824

Fitzova, H., Matulova, M., \& Tomes, Z. (2018). Determinants of urban public transport efficiency: case study of the Czech Republic. European Transport Research Review, 10(2). https://doi.org/10.1186/s12544-018-0311-y.

Hirschhorn, F., Veeneman, W., \& van de Velde, D. (2018). Inventory and rating of performance indicators and organisational features in metropolitan public transport: A worldwide Delphi survey. Research in Transportation Economics, 69(SI), 144-156. https://doi.org/10.1016/j.retrec.2018.02.003

Hirschhorn, F., Veeneman, W., \& van de Velde, D. (2019). Organisation and performance of public transport: A systematic cross-case comparison of metropolitan areas in Europe, Australia, and Canada. Transportation Research Part A: Policy and Practice, 124, 419-432. https://doi.org/10.1016/j.tra.2019.04.008

Lupták, V., Droździel, P., Stopka, O., Stopková, M., \& Rybicka, I. (2019). Approach Methodology for Comprehensive Assessing the Public Passenger Transport Timetable Performances at a Regional Scale. Sustainability, 11(13), 3532. https://doi.org/10.3390/su11133532

Matulova, M., \& Fitzova, H. (2018). Transformation of urban public transport financing and its effect on operators' efficiency: evidence from the Czech Republic. Central European Journal of Operations Research, 26(4:SI), 967-983. https://doi.org/10.1007/s10100-018-0565-4

Sydos. (2021). Transport yearbooks. Retrieved January 5, 2021, from https://www.sydos.cz/cs/rocenky.htm

Zhang, X., Zhang, Q., \& Sun, T. (2019). Performance evaluation and obstacle factors analysis of urban public transport priority. Transportation Planning and Technology, 42(7), 696-713.

https://doi.org/10.1080/03081060.2019.1650433 